\title{
Cardioprotective effects of adenosine within the border and remote areas of myocardial infarction
}

Mélanie Bousquenaud ${ }^{1}$, Fatiha Maskali², Sylvain Poussier ${ }^{2}$, Jennifer Zangrando ${ }^{1}$, Pierre-Yves Marie ${ }^{2,3}$, Henri Boutley², Renaud Fay ${ }^{4}$, Gilles Karcher ${ }^{2}$, Daniel R Wagner ${ }^{1,5}$ and Yvan Devaux ${ }^{1 *}$

\begin{abstract}
Background: Adenosine may have beneficial effects on left ventricular function after myocardial infarction (MI), but the magnitude of this effect on remote and $\mathrm{Ml}$ areas is controversial. We assessed the long-term effects of adenosine after $\mathrm{Ml}$ using electrocardiogram-triggered ${ }^{18}$ F-fluorodeoxyglucose positron emission tomography.

Methods: Wistar rats were subjected to coronary ligation and randomized into three groups treated daily for 2 months by $\mathrm{NaCl}$ (control; $n=7$ ), 2-chloroadenosine (CADO; $n=8)$ or CADO with 8-sulfophenyltheophilline, an antagonist of adenosine receptors (8-SPT; $n=8)$.

Results: After 2 months, control rats exhibited left ventricular remodelling, with increased end-diastolic volume and decreased ejection fraction. Left ventricular remodelling was not significantly inhibited by CADO. Segmental contractility, as assessed by the change in myocardial thickening after 2 months, was improved in CADO rats compared to control rats $(+1.6 \% \pm 0.8 \%$ vs. $-2.3 \% \pm 0.8 \%, p<0.001)$. This improvement was significant in border $(+5.6 \% \pm 0.8 \%$ vs. $+1.5 \% \pm 0.8 \%, p<0.001)$ and remote $(-4.0 \% \pm 1.0 \%$ vs. $-10.4 \% \pm 1.3 \%, p<0.001)$ segments, but absent in MI segments. Histological analyses revealed that CADO reduced fibrosis, cardiomyocyte hypertrophy and apoptosis. Protective effects of CADO were blunted by 8-SPT.
\end{abstract}

Conclusion: Long-term administration of adenosine protects the left ventricle from contractile dysfunction following Ml.

Keywords: Adenosine; Myocardial infarction; Contractility; Left ventricular remodelling; Gated cardiac positron emission tomography

\section{Background}

Despite reperfusion therapies, left ventricular (LV) remodelling occurs in many patients after acute myocardial infarction (MI), leading to a risk of subsequent heart failure [1]. This has stimulated efforts to develop new pharmacological strategies to prevent or reverse LV remodelling. LV remodelling is defined as a complex sequence of changes in left ventricle geometry and function $[2,3]$ involving progressive LV dilatation, cardiomyocyte hypertrophy and fibrosis, ultimately leading to the loss of contractile function and LV dysfunction. The long-term outcome of acute MI patients largely depends on the amount of the initial injury which conditions subsequent

\footnotetext{
* Correspondence: yvan.devaux@crp-sante.lu

'Laboratory of Cardiovascular Research, Centre de Recherche Public de la Santé, 84 Val Fleuri, Luxembourg L1526, Luxembourg

Full list of author information is available at the end of the article
}

LV remodelling. Thus, therapeutic strategies aiming at reducing infarct size and improving LV remodelling are of major interest.

Adenosine is a ubiquitous endogenous nucleoside that modulates physiological functions in various organs and plays important roles within the cardiovascular system. It can signal through four sub-types of $G$ proteincoupled receptors, all of which are expressed in the heart [4]. Cardioprotective properties of adenosine have been characterized, particularly during ischemic preconditioning. However, the long-term effect of adenosine after MI has received less attention.

Disappointing results were documented when adenosine was administrated during the acute phase of reperfused MI in humans [5-7]. However, further experimental data suggest that beneficial effects could be

\section{空}

(c) 2013 Bousquenaud et al.; licensee Springer. This is an Open Access article distributed under the terms of the Creative Commons Attribution License (http://creativecommons.org/licenses/by/2.0), which permits unrestricted use, distribution, and reproduction in any medium, provided the original work is properly cited. 
long-term administration of $\mathrm{A} 2 \mathrm{~B}$ adenosine receptor agonist in a rat infarct model improved global LV function assessed by echocardiography [8]. A recent study showed that infarct size could be reduced by increasing adenosine levels in transgenic swine through over-expression of ectonucleoside triphosphate diphosphohydrolase-1 (CD39) [9].

While adenosine appears to have certain beneficial effects after MI, the mechanisms and sites of these effects, as well as the consequences on global LV remodelling, are poorly documented. Therefore, the aim of the current study was to investigate the effects of long-term administration of adenosine on LV function and remodelling after MI by serial non-invasive imaging with electrocardiogram (ECG)-triggered ${ }^{18}$ F-fluorodeoxyglucose positron emission tomography (FDG-PET). FDG-PET has been reported as an imaging technique for assessing the severity and the location of MI and is also capable of quantifying global and segmental LV function [10,11]. Thus, FDG-PET allows for a separate analysis of the contractile function of MI, remote and border segments.

\section{Methods}

This study was performed in accordance with the regulations of the Animal Welfare Act of the National Institutes of Health Guide for the Care and Use of Laboratory Animals (NIH Publication No. 85-23, revised 1996), and protocols were approved by the Regional Veterinary Department ('Direction Départementale de la Protection des Populations'), agreements RAR1A03516811825 and 54-100.

\section{Animal model and experimental design}

Twenty-three adult male Wistar rats (282- to 335-g body weight at the beginning of the study; Charles Rivers Laboratories, Wilmington, MA, USA) were enrolled. All animals were housed on a 12-h light-dark cycle in a room with temperature and humidity control, and with ad libitum access to tap water and standard rodent food. Permanent occlusion of the left anterior descending (LAD) coronary artery was performed in 23 rats as previously described $[10,12]$. The choice of this model rather than a model of ischemia/reperfusion was based on preliminary experiments suggesting that adenosine may be more protective in large infarcts than small infarcts (not shown). Rats were anaesthetized by inhalation of an isoflurane/oxygen mixture ( $2 \%$ to $3 \%: 1.5 \% v / v)$ and were intubated and ventilated with a rodent ventilator (Harvard Apparatus, Holliston, MA, USA). The heart was exposed through a left lateral thoracotomy of the fifth intercostal space. After pericardial incision, the proximal part of the LAD ( 2 to $3 \mathrm{~mm}$ from the top of the left atrium) was ligated with a 7-0 Prolene suture (Ethicon, Somerville, NJ, USA). Perioperative lidocaine $(10 \mathrm{mg} / \mathrm{kg}$, Aguettant, Lyon, France) was used to provide a local anaesthesia and to reduce the incidence of ventricular tachycardia and fibrillation. Finally, the chest was closed in layers with a 2-0 Vicryl suture (Ethicon, Somerville, NJ, USA), the lungs were reinflated using positive-end expiratory pressure, and the endotracheal tube was removed once spontaneous breathing had resumed. Amoxicillin was injected intramuscularly (60 mg/kg, GlaxoSmithKline, Marly-le-Roi, France) to avoid bacterial infections. The mortality of the procedure was $<20 \%$.

Two days after surgery, rats were assessed by ECGtriggered ${ }^{18}$ F-FDG-PET. This first PET exam allowed for randomizing the animals into three treatment groups according to infarct size. This randomization was crucial to avoid any bias due to different infarct sizes in experimental groups. Infarct size is indeed a major determinant of LV remodelling. A three-point classification was used to determine MI size, as previously described by our team [10]: small MI (no more than 3 among the 17 LV segments), moderate MI (4 to 5 segments) and large MI (at least 6 MI segments). Groups were constituted in order to exhibit equivalent rates of rats with small, moderate and large MI. In each of the three groups, rats were assigned to treatment with $\mathrm{NaCl}$ (control group; $n=7$ ) or 2-chloroadenosine $(2 \mathrm{mg} / \mathrm{kg} /$ day $)$, a stable analogue of adenosine, which was given alone (CADO group; $n=8)$ or with 8 -sulfophenyltheophilline ( $10 \mathrm{mg} / \mathrm{kg} /$ day), an antagonist of adenosine receptors (8-SPT group; $n=8$ ). NaCl, CADO and 8-SPT (Sigma-Aldrich, Bornem, Belgium) were administered intraperitoneally twice daily for 2 months, starting 7 days after the date of LAD occlusion.

\section{${ }^{18}$ F-Fluorodeoxyglucose PET}

Two days, 1 month and 2 months after surgery, LV function and infarct size were assessed in vivo by FDG-PET. As already described in detail elsewhere $[10,13]$, rats received an oral pre-medication of $50 \mathrm{mg} / \mathrm{kg}$ of acipimox, a potent nicotinic acid derivative yielding high-quality cardiac FDG-PET images. Around 74 MBq of ${ }^{18}$ F-FDG (IBA, Nancy, France) were injected intravenously under a transient anaesthesia with isoflurane. A 16-min recording was started $1 \mathrm{~h}$ later on a high-resolution dedicated small animal PET system (Inveon, Siemens, Knoxville, TN, USA) and under continuous anaesthesia by isoflurane. Images were reconstructed in 16 cardiac intervals with a 3-D ordered subset expectation maximization algorithm leading to a voxel size of $0.8 \times 0.4 \times 0.4 \mathrm{~mm}$.

FDG uptake was determined on the set of collapsed short-axis slices in each segment from the 17-segment LV division from the American Heart Association [14] with the QGS software [15]. LV end-diastolic volume (EDV), LV end-systolic volume (ESV) and ejection fraction (EF) were obtained from the set of contiguous ECG-triggered short-axis slices with the QGS software 
$[15,16]$. The accuracy of these volume measurements was previously demonstrated on phantoms from LV rats above the level of $100 \mu \mathrm{L}$, corresponding to the lower limit for the LV end-systolic volume in adult rats [13]. The QGS software was also used for assessing the contractility of each of the $17 \mathrm{LV}$ segments according to the percentage of systolic increase in myocardial counts
[15]. This parameter is strongly linked to the percentage of myocardial thickening with both myocardial SPECT and TEP imaging techniques $[17,18]$.

As previously described and validated [10], all segments for which the average FDG uptake was very low ( $<50 \%$ of the maximal voxel value) could be considered as predominantly necrotic, and the percentage of such

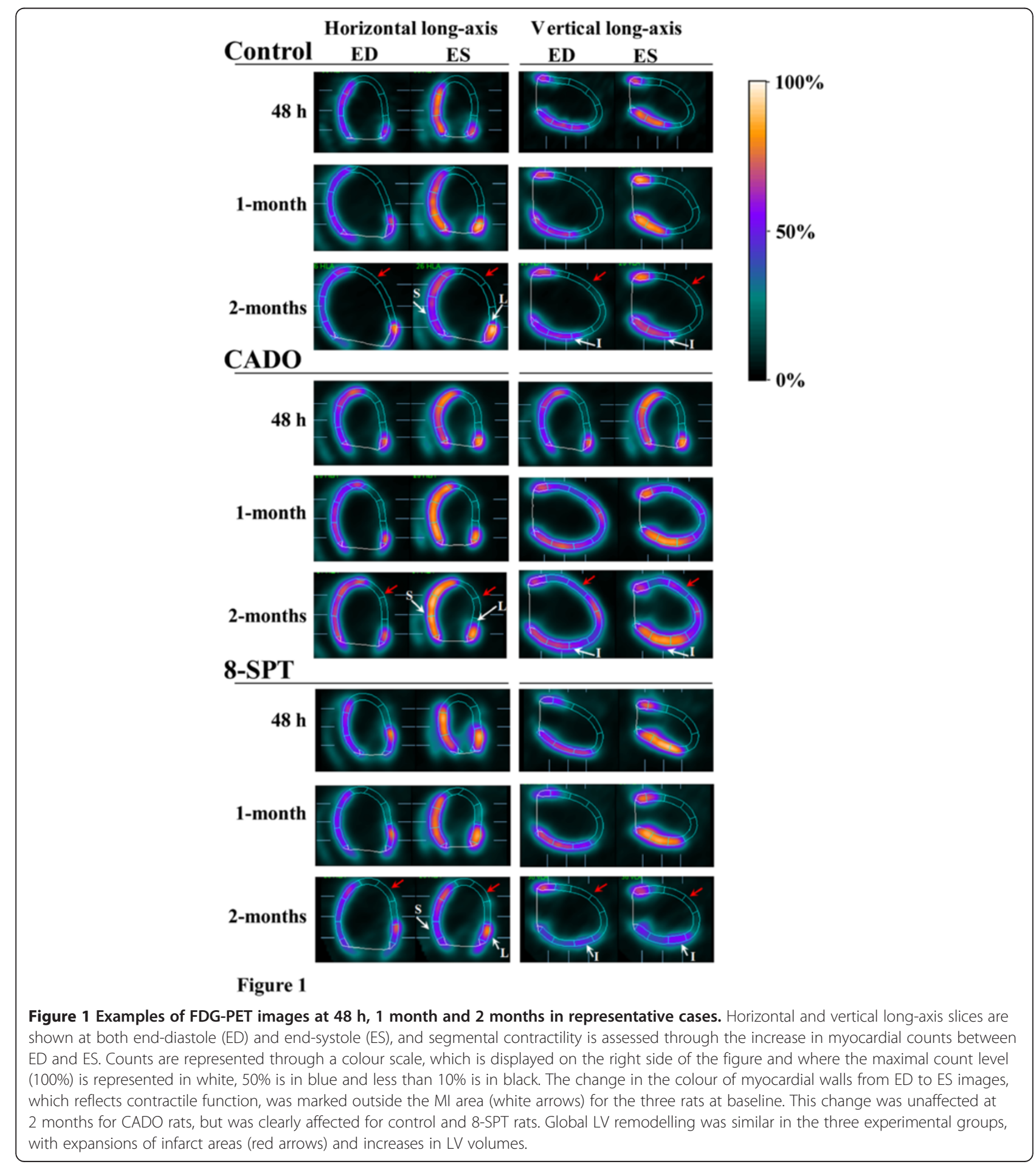


segments was used to assess the extent of MI areas. For the segmental analysis of LV contractility, MI segments were defined as those showing a very low FDG uptake $(<50 \%$ of the maximal voxel value) on the entire segment area, remote segments were defined as those which were not adjacent to any segment showing such a low uptake, and the remaining segments were considered to be within the border zone.

The average heart rate value during PET acquisition was extracted from the list mode recording data. Systolic blood pressure was calculated as the mean value of four recordings by the tail-cuff method during the PET acquisition (AD Instruments, Powerlab, Paris, France).

\section{Histological analyses}

Rats were sacrificed 1 to 2 days after the last 2 months of PET acquisition with an overdose of sodium pentobarbital. The hearts were excised, snap frozen in liquid nitrogen, fixed and embedded in optimal cutting media (VWR, Fontenay-sous-Bois, France). Contiguous sections $(8 \mu \mathrm{m})$, orientated along the vertical or horizontal long axis of the

Table 1 Cardiac FDG-PET parameters

\begin{tabular}{|c|c|c|c|}
\hline & $\begin{array}{c}\text { Control } \\
(n=7)\end{array}$ & $\begin{array}{l}\text { CADO } \\
(n=8)\end{array}$ & $\begin{array}{l}\text { 8-SPT } \\
(n=8)\end{array}$ \\
\hline \multicolumn{4}{|l|}{$48 \mathrm{~h}$} \\
\hline Extent of Ml area (\% of LV) & $35 \pm 6$ & $32 \pm 15$ & $32 \pm 21$ \\
\hline $\mathrm{EDV}(\mu \mathrm{L})$ & $412 \pm 61$ & $397 \pm 57$ & $441 \pm 66$ \\
\hline ESV $(\mu \mathrm{L})$ & $239 \pm 48$ & $230 \pm 43$ & $257 \pm 74$ \\
\hline $\mathrm{EF}(\%)$ & $42 \pm 7$ & $42 \pm 6$ & $42 \pm 7$ \\
\hline \multicolumn{4}{|l|}{1 month } \\
\hline Extent of $\mathrm{Ml}$ area (\% of LV) & $32 \pm 9$ & $29 \pm 14$ & $33 \pm 23$ \\
\hline Change from $48 \mathrm{~h}$ & $-3 \pm 7$ & $-3 \pm 4$ & $1 \pm 7$ \\
\hline EDV $(\mu \mathrm{L})$ & $600 \pm 95$ & $576 \pm 111$ & $666 \pm 175$ \\
\hline Change from $48 \mathrm{~h}$ & $188 \pm 76$ & $179 \pm 120$ & $225 \pm 160$ \\
\hline $\mathrm{ESV}(\mu \mathrm{L})$ & $353 \pm 67$ & $324 \pm 106$ & $428 \pm 185$ \\
\hline Change from $48 \mathrm{~h}$ & $114 \pm 61$ & $94 \pm 112$ & $171 \pm 149$ \\
\hline EF (\%) & $42 \pm 2$ & $45 \pm 9$ & $38 \pm 12$ \\
\hline Change from $48 \mathrm{~h}$ & $0 \pm 8$ & $3 \pm 10$ & $-5 \pm 7$ \\
\hline \multicolumn{4}{|l|}{2 months } \\
\hline Extent of $\mathrm{Ml}$ area (\% of LV) & $30 \pm 11$ & $26 \pm 15$ & $32 \pm 27$ \\
\hline Change from $48 \mathrm{~h}$ & $-5 \pm 9$ & $-7 \pm 8$ & $0 \pm 9$ \\
\hline $\mathrm{EDV}(\mu \mathrm{L})$ & $692 \pm 132$ & $637 \pm 151$ & $780 \pm 232$ \\
\hline Change from $48 \mathrm{~h}$ & $280 \pm 113$ & $241 \pm 158$ & $339 \pm 212$ \\
\hline ESV $(\mu \mathrm{L})$ & $432 \pm 120$ & $379 \pm 149$ & $530 \pm 210$ \\
\hline Change from $48 \mathrm{~h}$ & $19 \pm 99$ & $149 \pm 145$ & $273 \pm 174$ \\
\hline EF (\%) & $38 \pm 5$ & $42 \pm 8$ & $34 \pm 10$ \\
\hline Change from $48 \mathrm{~h}$ & $-4 \pm 6$ & $0 \pm 8$ & $-9 \pm 6$ \\
\hline
\end{tabular}

LV (depending on infarct location), were obtained in a cryostat at $-22^{\circ} \mathrm{C}$ and stored at $-80^{\circ} \mathrm{C}$ until analysis.

The degree of fibrosis in heart sections was assessed by Masson's trichrome staining. The collagen volume fraction was measured while omitting fibrosis of the perivascular, epicardial and endocardial areas [19]. The fibrosis area in the border zone was measured in three random fields per heart section ( $\times 400$ magnification) by dividing the area of collagen to the total area and using ImageJ version 1.42 (http://rsbweb.nih.gov/ij/index.html).

Haematoxylin and eosin staining was performed to assess the cross-sectional area of cardiomyocytes in heart sections. For each section, at least five cardiomyocytes sectioned transversely were randomly chosen, and their area was quantified using ImageJ software. The average area was calculated for each experimental group.

Immunohistochemical staining was performed for annexin-5 apoptosis marker using a rabbit polyclonal antibody (Abcam, Cambridge, UK). Alexa Fluor ${ }^{\circ}$ 635coupled goat anti-rabbit antibody was used as secondary antibody (Invitrogen, Merelbeke, Belgium). Technical controls without primary antibody were performed for each marker to ensure staining specificity. DAPI was used to reveal nuclei. Images were recorded on a confocal microscope (Zeiss Laser Scanning Microscope LSM 510, Carl Zeiss Microscopy, Oberkochen, Germany) with a x

Table 2 Body weight, heart rate and blood pressure

\begin{tabular}{|c|c|c|c|}
\hline & $\begin{array}{c}\text { Control } \\
(n=7)\end{array}$ & $\begin{array}{l}\text { CADO } \\
(n=8)\end{array}$ & $\begin{array}{l}\text { 8-SPT } \\
(n=8)\end{array}$ \\
\hline \multicolumn{4}{|l|}{$48 \mathrm{~h}$} \\
\hline Body weight (g) & $312 \pm 25$ & $307 \pm 35$ & $307 \pm 20$ \\
\hline Systolic blood pressure $(\mathrm{mmHg})$ & $104 \pm 3$ & $107 \pm 8$ & $102 \pm 7$ \\
\hline Heart rate (bpm) & $419 \pm 14$ & $403 \pm 38$ & $422 \pm 21$ \\
\hline \multicolumn{4}{|l|}{1 month } \\
\hline Body weight (g) & $353 \pm 22$ & $332 \pm 30$ & $332 \pm 27$ \\
\hline Change from $48 \mathrm{~h}$ & $41 \pm 15$ & $25 \pm 14$ & $25 \pm 22$ \\
\hline Systolic blood pressure $(\mathrm{mmHg})$ & $106 \pm 4$ & $106 \pm 4$ & $104 \pm 4$ \\
\hline Change from $48 \mathrm{~h}$ & $2 \pm 4$ & $-2 \pm 8$ & $2 \pm 7$ \\
\hline Heart rate (bpm) & $374 \pm 31$ & $338 \pm 35^{*}$ & $335 \pm 48$ \\
\hline Change from $48 \mathrm{~h}$ & $-45 \pm 36$ & $-66 \pm 69$ & $-87 \pm 60$ \\
\hline \multicolumn{4}{|l|}{2 months } \\
\hline Body weight (g) & $402 \pm 12$ & $363 \pm 26^{*}$ & $376 \pm 45$ \\
\hline Change from $48 \mathrm{~h}$ & $90 \pm 22$ & $56 \pm 29$ & $69 \pm 43$ \\
\hline Systolic blood pressure $(\mathrm{mmHg})$ & $104 \pm 4$ & $104 \pm 3$ & $104 \pm 5$ \\
\hline Change from $48 \mathrm{~h}$ & $0 \pm 5$ & $-3 \pm 6$ & $2 \pm 10$ \\
\hline Heart rate (bpm) & $383 \pm 22$ & $338 \pm 33^{*}$ & $353 \pm 39$ \\
\hline Change from $48 \mathrm{~h}$ & $-36 \pm 27$ & $-66 \pm 44$ & $-68 \pm 36$ \\
\hline
\end{tabular}

${ }^{*} p<0.05$ for unpaired comparisons vs. control group. 
400 magnification using the LSM 510 META software (Carl Zeiss Microscopy, Oberkochen, Germany).

\section{Statistical analysis}

Analyses were performed using the SAS R9.3 software (SAS Institute, Cary, NC, USA), and the two-tailed significance level was set to $p<0.05$.

Pairwise comparisons of quantitative variables between the CADO or 8-SPT group and the control group were carried out using the Mann-Whitney test, and corresponding variables were expressed with mean \pm standard error of the mean (SEM).

Segmental contractility was analysed over time using repeated measures mixed ANOVA: (1) with treatment group and segment location as fixed factors and (2) with rat as a random factor nested within the 'treatment' variable (all segments from a single rat received the same treatment). The results of these analyses were expressed as adjusted means \pm SEM. Validity conditions of the models were thoroughly checked (normality of residuals, homoscedasticity and absence of collinearity or interaction). These global analyses were conducted for assessing, first, the effect of CADO alone (CADO vs. control) and, thereafter, the effect of CADO associated with 8-SPT (8-SPT vs. control). In order to preserve the overall $5 \%$ alpha error rate, the comparisons of CADO or 8-SPT vs. control were carried out at the $2.5 \%$ level.

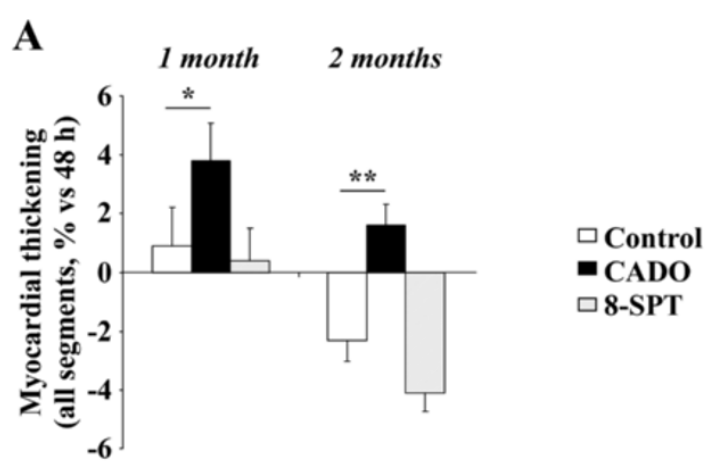

B
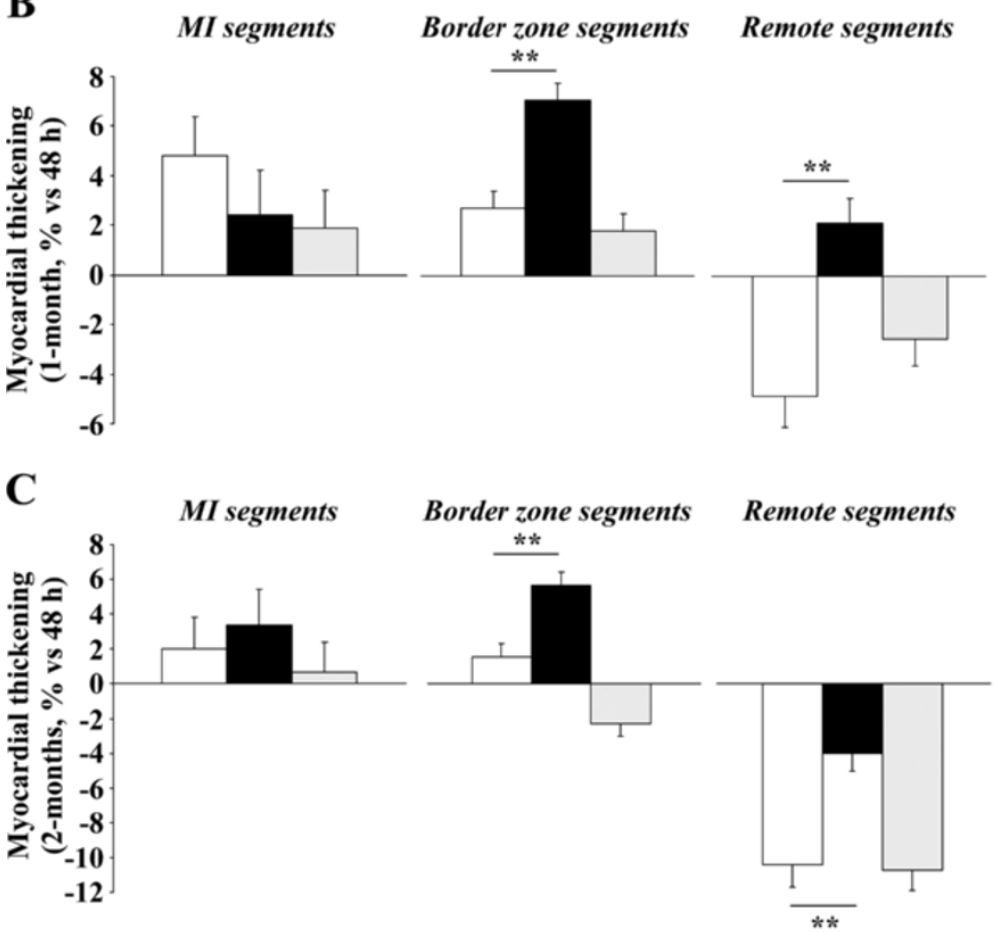

Figure 2 CADO treatment improves segmental contractile function in remote regions after MI. The evolution of segmental contractility in the three experimental groups is expressed as the change from $48 \mathrm{~h}$ to 1 and 2 months of the percentage of myocardial thickening. (A) Global evolution of segmental contractility (i.e. whole heart). (B, C) Evolution of segmental contractility after 1 and 2 months according to segment location (Ml, border zone or remote area). Data are adjusted mean \pm SEM. ${ }^{*} p<0.01 ;{ }^{* *} p<0.001$. 


\section{Results}

\section{Early FDG-PET imaging and randomization}

Representative FDG-PET images obtained at $48 \mathrm{~h}, 1$ month and 2 months are shown in Figure 1. On the baseline FDGPET scans recorded 2 days after coronary occlusion, necrotic segments were observed in all 23 animals. According to the three-point classification of MI size (small, moderate and large MI) [10], rats were subsequently randomized into three treatment groups: control $(n=7)$, CADO $(n=8)$ and 8 -SPT $(n=8)$. Thus, the mean infarct size was equivalent between the three groups (Table 1). The mean baseline values of LV volumes, LV ejection fraction, heart rate, blood pressure and body weight were also similar between the three groups (Tables 1 and 2).

\section{Evolution of body mass, hemodynamic parameters and global LV function}

During the 2-month follow-up, all rats showed an increase in body weight, a decrease in heart rate and a stable level of systolic blood pressure. At 2 months, however, body weight and heart rate were slightly but significantly lower in CADO-treated rats than in control rats (Table 2).

As detailed in Table 1, control rats exhibited marked LV remodelling during the 2-month follow-up, as attested by increased EDV and ESV, and decreased EF. These changes were not significantly different in the
CADO group or in the 8-SPT group, even though there were trends toward a beneficial effect on LV volumes and $\mathrm{EF}$ in the CADO group and a detrimental effect on LV volumes and EF in the 8-SPT group (Table 1).

\section{Evolution of segmental contractility}

Seventeen segments were analysed in each of the 23 animals, leading to a total of 391 analysed segments. On the 2-day FDG-PET exams, 43 segments were totally necrotic (MI segments), 109 were considered as remote segments and the 239 remaining segments were considered to be within the border zone. Myocardial thickening, assessed through the percentage of systolic increase in myocardial counts, exhibited a continuous decline between remote $(40 \% \pm 9 \%)$, border zone $(23 \% \pm 13 \%)$ and MI $(12 \% \pm 4 \%)$ segments $(p<0.001)$.

Analyses of variance revealed that the evolution of myocardial thickening over 2 months was enhanced in CADO-treated rats, compared to control rats, with a significant interaction by segment location (remote, border zone or MI area) $(p=0.03)$. In contrast, no difference was observed when 8-SPT rats were compared to control rats using the same model.

Changes in segmental contractility from baseline were also compared between the three groups at the specific time-points of 1 and 2 months, as detailed in Figure 2. The main observation was that, on average, the
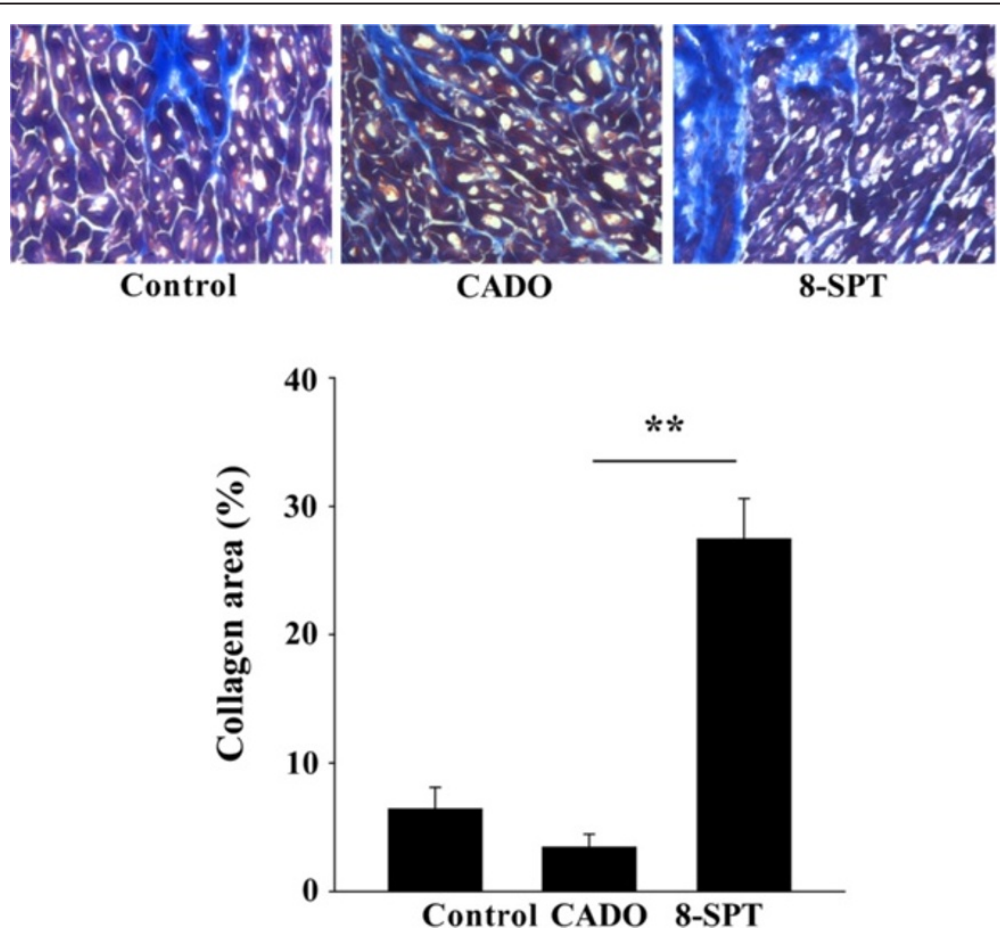

Figure 3 8-SPT treatment aggravates cardiac fibrosis. Upper panel: cardiac sections of non-infarcted areas of the left ventricle stained with Masson's trichrome. Representative pictures from the three experimental groups are shown. Magnification, $\times 400$. Lower panel: quantitative analysis of collagen volume fraction in non-infarcted areas. Results are mean \pm SEM. ${ }^{*} p<0.001$. 
contractile function of the overall segments from CADO rats was enhanced when compared to controls at 1 and 2 months (Figure 2A). After 1 month, the increase of myocardial thickening was $+3.8 \% \pm 0.7 \%$ in the CADO group compared to $+0.9 \% \pm 0.7 \%$ in the control group $(p<0.01)$. After 2 months, contractile function was impaired in control rats, as attested by a decrease of myocardial thickening of $-2.3 \% \pm 0.8 \%$, and preserved in CADO-treated rats $(+1.6 \% \pm 0.8 \%, p<0.001)$. This effect of CADO was blunted by 8-SPT (Figure 2A).

Interestingly, the beneficial effect of CADO on contractile function varied according to segment location, both after 1 month (Figure 2B) and after 2 months (Figure 2C). In particular, at 2 months, this effect was obvious (1) in the border zone where CADO rats exhibited a significant increase in contractile function $(+5.6 \% \pm 0.8 \%)$, whereas control rats did not $(+1.5 \% \pm$ $0.8 \%, p<0.001$ vs. CADO), and (2) in remote segments where a decline in contractile function was documented in all groups but to a lower extent in the CADO group $(-4.0 \% \pm 1.0 \%)$ than in the control group $(-10.4 \% \pm 1.3 \%, p<0.001$ vs. CADO $)$. By contrast, the contractile function of MI segments was stable and comparable in the two groups at 2 months (CADO $+3.4 \% \pm$ $2.0 \%$ vs. control $+2.0 \% \pm 1.8 \%, p=\mathrm{NS}$ ).

The beneficial effect of CADO on the contractile function of the border and remote segments was lost for rats additionally treated with 8-SPT (Figure 2A,B).

\section{Fibrosis, cardiomyocyte hypertrophy and apoptosis}

We examined the extent of fibrosis outside the MI areas (Figure 3). CADO appeared to reduce fibrosis in remote areas, when compared to controls, although this difference did not reach the level of statistical significance. However, this fibrosis was markedly increased by the administration of 8-SPT (eightfold increase compared to the CADO group, $p<0.001$ ).

The cardiomyocyte cross-sectional area in healthy parts of the heart was lower in the CADO than in the control group, and this effect was blunted by 8 -SPT (Figure 4).

Annexin-5 staining was reduced in CADO rats compared to control rats and was robustly increased by 8 SPT (Figure 5). These differences were evident in the remote and border zones.

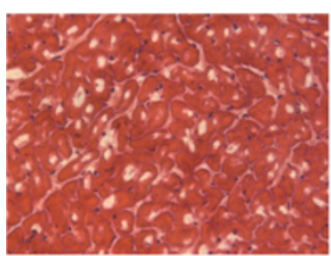

Control

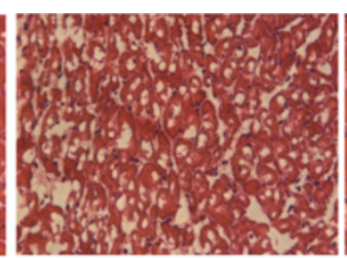

CADO

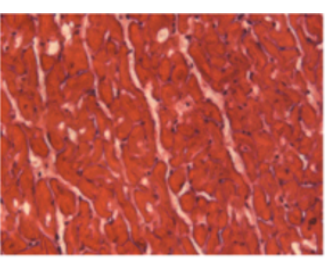

8-SPT

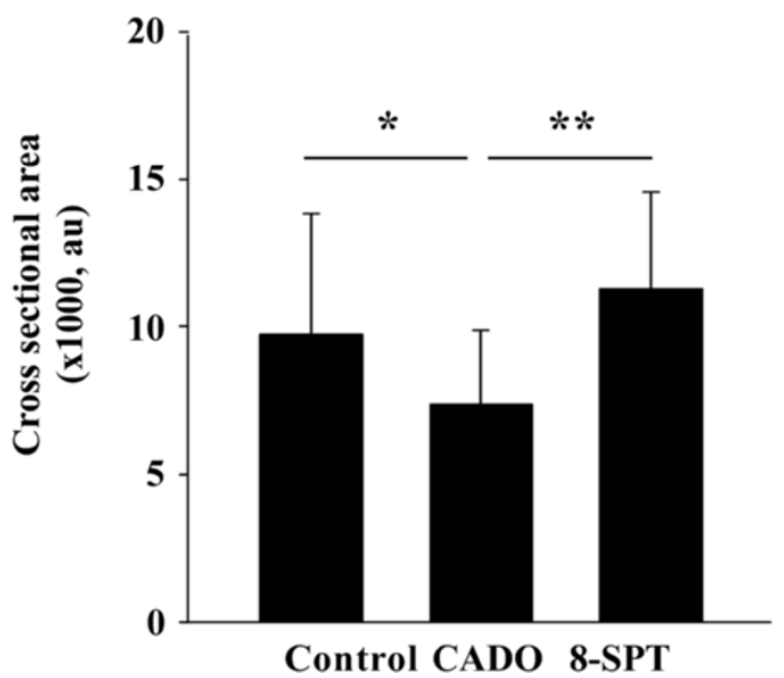

Figure 4 CADO treatment limits cardiomyocyte hypertrophy. Upper panel: representative histological sections stained with haematoxylin and eosin in remote areas showing cardiomyocyte hypertrophy. Lower panel: quantitative analysis of the cross-sectional area of cardiomyocytes from remote areas. Cardiomyocyte hypertrophy was decreased in CADO-treated rats compared to control rats. Results are mean \pm SEM. au, arbitrary units. ${ }^{*} p<0.005 ;{ }^{* *} p<0.001$. Magnification, $\times 400$. 


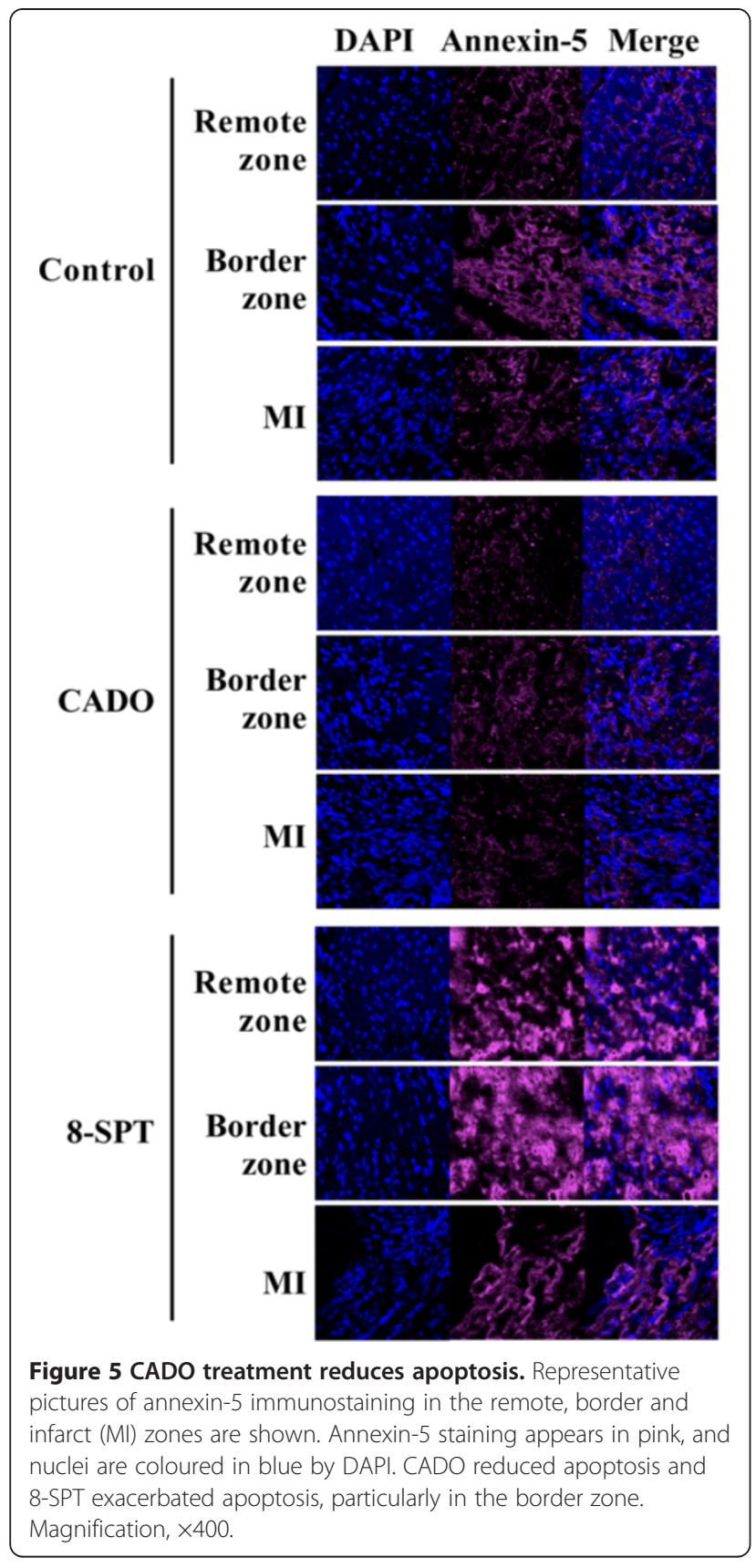

Therefore, activation of adenosine receptors reduces MIinduced fibrosis, cardiomyocyte hypertrophy and apoptosis.

\section{Discussion}

Using FDG-PET in a rat infarct model, the present study shows that adenosine provides beneficial effects within the remote and border zones, but not within the MI area. However, these effects have a limited impact on global LV remodelling.

We have previously shown that the method of acipimox-enhanced FDG-PET provides cardiac images of a very high quality in rats [13], as well as accurate assessments of LV function and of MI size and location in the experimental model of LAD occlusion [10]. In the present study, the FDG-PET exams, performed $48 \mathrm{~h}$ after surgery, allowed for randomizing the animals into different treatment groups according to initial infarct size. This size, which is highly variable in the rat model, constitutes a main determinant of subsequent LV remodelling in the rat model [10]. Therefore, such a pretherapeutic randomization was critical for providing an accurate comparison with the control group. This was not done in the previous echocardiographic study of long-term adenosine A2B receptor stimulation [8].

In addition, the FDG-PET technique allowed for a separate survey of the contractile function of the MI, remote and border segments. These data showed that treatment with CADO was beneficial on the contractile function of the segments lying outside the MI area. CADO treatment inhibited the progressive decline in the contractile function of remote areas and enhanced the contractile function within the border zone. These effects were truly attributable to the stimulation of adenosine receptors since they were abolished when a panantagonist of adenosine receptors was added to CADO treatment (8-SPT group).

The observation of a protective effect in the border zone is clinically relevant since the border zone is considered as a main therapeutic target after MI. For instance, injection of stem cells into the border zone has been shown to enhance vascular density and contractile performance in animals [20]. Similar results were achieved by the co-expression of vascular endothelial growth factor and angiopoietin-1 in the infarct border zone [21]. In addition, we have previously shown that the perfusion of the infarct border zone was enhanced after the injection of stem cells within the infarct core [22]. However, these therapeutic approaches are not easy to apply, whereas the present study shows that a simple pharmacological treatment is able to improve myocardial contractility.

The exact mechanism by which the stimulation of adenosine receptors improves contractile function in the border and remote zones remains to be fully defined. We observed a mild lowering of heart rate after 2 months of CADO treatment, but this is unlikely to fully explain the cardioprotective effects of CADO. Previous in vitro experiments from our group have shown that adenosine regulates multiple pathways involved in LV remodelling, such as inflammation, angiogenesis and extracellular matrix turnover [23-26]. In the present in vivo study, we further extend the cardioprotective properties of adenosine to apoptosis, consistent with a previous report by Simonis et al. [27], fibrosis [8] and cardiomyocyte hypertrophy [28]. All together, these results suggest that 
therapeutic targeting of adenosine receptors may have multiple cardioprotective effects.

Angiotensin-converting enzyme (ACE) inhibitors and beta-blockers are currently used to limit LV remodelling after MI. Although their effects on global function and on the limitation of infarct expansion are well documented [29], their effects in the border zone are still poorly known. Beta-blockers may only have a limited effect in the border zone because of multiple defects in the membrane beta-adrenergic receptor complex in the infarcted heart [30]. Our results, showing a preservation of contractile function in remote and border zones, but no effect on the infarct area, suggest that adenosine may target other signalling pathways than ACE inhibitors and beta-blockers. Whether adenosine exerts complementary cardioprotective effects to ACE inhibitors and betablockers could be the subject of further studies.

In our study, CADO was unable to significantly protect the heart from the development of adverse LV remodelling, as assessed by LV volumes and EF. These results differ from those of Wakeno and colleagues [8], where a selective adenosine $\mathrm{A} 2 \mathrm{~B}$ receptor agonist was reported to prevent LV remodelling after MI. In that study, LV function was assessed in only two dimensions by echocardiography and there was no documentation that the different experimental groups had equivalent infarct size before treatment. A2B receptors play critical roles in the reduction of remodelling and in the revascularization of the infarcted heart induced by mesenchymal stem cells [31]. Activation of A2B receptors inhibits apoptosis after MI [27]. However, a specific blockade of A2B receptors has been also shown to limit LV remodelling after MI [32]. The cardioprotective properties of $\mathrm{A} 2 \mathrm{~B}$ receptors are therefore complex and have been recently reviewed [33].

The roles of $\mathrm{A} 1$ and $\mathrm{A} 3$ receptors are also multiple and complex in this setting. Initial studies by Matherne and colleagues indicated that activation of the A1 adenosine receptor protects from myocardial ischemia [34]. This observation was subsequently confirmed by other groups (reviewed in [35]). The failure of CADO, a preferential A1 receptor agonist, to protect from LV remodelling in our study might be related to A3 activation, which has shown deleterious cardiac effects [36]. On the opposite, the A3 receptor has also cardioprotective properties [37].

Finally, all four sub-types of adenosine receptors appear to have the potential to exert cardioprotective effects after ischemia. Adenosine has multiple effects on several components of LV remodelling such as inflammation, fibrosis, angiogenesis, apoptosis, etc. These effects rely on the sub-type of adenosine receptors present on the cell surface. It remains to be determined whether the activation or blockade of several sub-types of adenosine receptors has superior anti-remodelling effects than the preferential activation of one receptor. It will also be interesting in future studies to address the cardioprotective effects of adenosine in a model of ische$\mathrm{mia} /$ reperfusion, which more closely resembles the clinical MI setting.

\section{Conclusions}

We have shown that, when administrated long-term after MI, adenosine exerts beneficial effects on the myocardial contractility of remote and border zones, but with limited impact on global LV remodelling. Further studies are required to determine the therapeutic potential of this observation.

\section{Competing interests}

The authors declare that they have no competing interests.

\section{Authors' contributions}

$M B$ performed the animal experiments and participated in the data analysis and manuscript drafting. FM, SP and HB participated in the PET exams and image analysis. JZ participated in the ex vivo experiments. RF performed the statistical analysis. GK and DW participated in the study design and manuscript drafting. YD and PYM supervised the study and drafted the manuscript. All authors read and approved the final manuscript.

\section{Acknowledgements}

This work was supported by the Society for Research on Cardiovascular Diseases and the Ministry of Culture, Higher Education and Research of Luxembourg. MB and JZ are recipients of fellowships from the National Fund for Research of Luxembourg (grants \# PhD-AFR 08-024 and \# 3972501, respectively)

\section{Author details}

'Laboratory of Cardiovascular Research, Centre de Recherche Public de la Santé, 84 Val Fleuri, Luxembourg L1526, Luxembourg. ${ }^{2}$ Nancyclotep Experimental Imaging Platform, 54 511, Nancy, France. ${ }^{3}$ INSERM, U1116, 54 000, Nancy, France. ${ }^{4}$ INSERM, Centre d'Investigation Clinique CIC-P 9501, Nancy 54000, France. ${ }^{5}$ Division of Cardiology, Centre Hospitalier, Luxembourg L-1210, Luxembourg.

Received: 17 June 2013 Accepted: 31 August 2013

Published: 12 September 2013

\section{References}

1. Wolk MJ, Scheidt S, Killip T: Heart failure complicating acute myocardial infarction. Circulation 1972, 45:1125-1138.

2. Jessup M, Brozena S: Heart failure. N Engl J Med 2003, 348:2007-2018.

3. Cohn JN, Ferrari R, Sharpe N: Cardiac remodeling-concepts and clinical implications: a consensus paper from an international forum on cardiac remodeling: behalf of an international forum on cardiac remodeling. J Am Coll Cardiol 2000, 35:569-582.

4. Headrick JP, Peart JN, Reichelt ME, Haseler LJ: Adenosine and its receptors in the heart: regulation, retaliation and adaptation. Biochimica et Biophysica Acta (BBA) - Biomembranes 2011, 1808:1413-1428.

5. Kloner RA, Forman MB, Gibbons RJ, Ross AM, Alexander RW, Stone GW: Impact of time to therapy and reperfusion modality on the efficacy of adenosine in acute myocardial infarction: the AMISTAD-2 trial. Eur Heart $J$ 2006, 27:2400-2405.

6. Desmet W, Bogaert J, Dubois C, Sinnaeve P, Adriaenssens T, Pappas C, Ganame J, Dymarkowski S, Janssens S, Belmans A, Van de Werf F: Highdose intracoronary adenosine for myocardial salvage in patients with acute ST-segment elevation myocardial infarction. Eur Heart J 2011, 32:867-877

7. Fokkema ML, Vlaar PJ, Vogelzang M, Gu YL, Kampinga MA, de Smet BJ, Jessurun GA, Anthonio RL, van den Heuvel AF, Tan ES, Zijlstra F: Effect of high-dose intracoronary adenosine administration during primary 
percutaneous coronary intervention in acute myocardial infarction: a randomized controlled trial. Circ Cardiovasc Interv 2009, 2:323-329.

8. Wakeno M, Minamino T, Seguchi O, Okazaki H, Tsukamoto O, Okada K, Hirata A, Fujita M, Asanuma H, Kim J, Komamura K, Takashima S, Mochizuki $\mathrm{N}$, Kitakaze M: Long-term stimulation of adenosine $\mathrm{A} 2 \mathrm{~b}$ receptors begun after myocardial infarction prevents cardiac remodeling in rats. Circulation 2006, 114:1923-1932.

9. Wheeler DG, Joseph ME, Mahamud SD, Aurand WL, Mohler PJ, Pompili VJ, Dwyer KM, Nottle MB, Harrison SJ, d'Apice AJ, Robson SC, Cowan PJ, Gumina RJ: Transgenic swine: expression of human CD39 protects against myocardial injury. J Mol Cell Cardiol 2012, 52:958-961.

10. Bousquenaud M, Maskali F, Poussier S, Marie PY, Boutley H, Karcher G, Wagner DR, Devaux Y: Acipimox-enhanced (18)F-fluorodeoxyglucose positron emission tomography for characterizing and predicting early remodeling in the rat infarct model. Int J Cardiovasc Imaging 2012, 28:1407-1415

11. Maskali F, Poussier S, Marie PY, Tran N, Antunes L, Olivier P, Plenat F, Maitrejean S, Zannad F, Karcher G: High-resolution simultaneous imaging of SPECT, PET, and MRI tracers on histologic sections of myocardial infarction. J Nucl Cardiol 2005, 12:229-230.

12. Pfeffer MA, Pfeffer JM, Fishbein MC, Fletcher PJ, Spadaro J, Kloner RA, Braunwald E: Myocardial infarct size and ventricular function in rats. Circ Res 1979, 44:503-512.

13. Poussier S, Maskali F, Tran N, Person C, Maureira P, Boutley H, Karcher G, Lacolley P, Regnault V, Fay R, Marie PY: ECG-triggered (18)F-

fluorodeoxyglucose positron emission tomography imaging of the rat heart is dramatically enhanced by acipimox. Eur J Nucl Med Mol Imaging 2010, 37:1745-1750.

14. Cerqueira MD, Weissman NJ, Dilsizian V, Jacobs AK, Kaul S, Laskey WK, Pennell DJ, Rumberger JA, Ryan T, Verani MS: Standardized myocardial segmentation and nomenclature for tomographic imaging of the heart: a statement for healthcare professionals from the Cardiac Imaging Committee of the Council on Clinical Cardiology of the American Heart Association. Circulation 2002, 105:539-542.

15. Germano G, Kiat H, Kavanagh PB, Moriel M, Mazzanti M, Su HT, Van Train KF, Berman DS: Automatic quantification of ejection fraction from gated myocardial perfusion SPECT. J NuCl Med 1995, 36:2138-2147.

16. Germano G, Kavanagh PB, Berman DS: An automatic approach to the analysis, quantitation and review of perfusion and function from myocardial perfusion SPECT images. Int J Card Imaging 1997, 13:337-346.

17. Marie PY, Djaballah W, Franken PR, Vanhove C, Muller MA, Boutley $H$, Poussier S, Olivier P, Karcher G, Bertrand A: OSEM reconstruction, associated with temporal fourier and depth-dependant resolution recovery filtering, enhances results from sestamibi and 201TI 16-interval gated SPECT. J Nucl Med 2005, 46:1789-1795.

18. Slart RH, Bax JJ, van Veldhuisen DJ, van der Wall EE, Dierckx RA, de Boer J, Jager PL: Prediction of functional recovery after revascularization in patients with coronary artery disease and left ventricular dysfunction by gated FDG-PET. J Nucl Cardiol 2006, 13:210-219.

19. Soeki T, Kishimoto I, Okumura H, Tokudome T, Horio T, Mori K, Kangawa K: C-type natriuretic peptide, a novel antifibrotic and antihypertrophic agent, prevents cardiac remodeling after myocardial infarction. J Am Coll Cardiol 2005, 45:608-616

20. Wang X, Jameel MN, Li Q, Mansoor A, Qiang X, Swingen C, Panetta C, Zhang J: Stem cells for myocardial repair with use of a transarterial catheter. Circulation 2009, 120:S238-246.

21. Tao Z, Chen B, Tan X, Zhao Y, Wang L, Zhu T, Cao K, Yang Z, Kan YW, Su H: Coexpression of VEGF and angiopoietin-1 promotes angiogenesis and cardiomyocyte proliferation reduces apoptosis in porcine myocardial infarction (MI) heart. Proc Natl Acad Sci U S A 2011, 108:2064-2069.

22. Tran N, Franken PR, Maskali F, Nloga J, Maureira P, Poussier S, Groubatch F, Vanhove C, Villemot JP, Marie PY: Intramyocardial implantation of bone marrow-derived stem cells enhances perfusion in chronic myocardial infarction: dependency on initial perfusion depth and follow-up assessed by gated pinhole SPECT. J NuCl Med 2007, 48:405-412.

23. Ernens I, Rouy D, Velot E, Devaux $Y$, Wagner DR: Adenosine inhibits matrix metalloproteinase-9 secretion by neutrophils: implication of A2A receptor and CAMP/PKA/Ca2+ pathway. Circ Res 2006, 99:590-597.

24. Velot E, Haas B, Leonard F, Ernens I, Rolland-Turner M, Schwartz C, Longrois D, Devaux $Y$, Wagner DR: Activation of the adenosine-A3 receptor stimulates matrix metalloproteinase- 9 secretion by macrophages. Cardiovasc Res 2008 , 80:246-254.

25. Leonard F, Devaux Y, Vausort M, Ernens I, Rolland-Turner M, Wagner DR: Adenosine modifies the balance between membrane and soluble forms of Flt-1. J Leukoc Biol 2011, 90:199-204.

26. Rolland-Turner M, Goretti E, Bousquenaud M, Leonard F, Nicolas C, Zhang L, Maskali F, Marie PY, DevauX Y, Wagner D: Adenosine stimulates the migration of human endothelial progenitor cells: role of CXCR4 and microRNA-150. PLOS ONE 2013, 8:e54135.

27. Simonis G, Wiedemann S, Joachim D, Weinbrenner C, Marquetant R, Strasser $\mathrm{RH}$ : Stimulation of adenosine $\mathrm{A} 2 \mathrm{~b}$ receptors blocks apoptosis in the non-infarcted myocardium even when administered after the onset of infarction. Mol Cell Biochem 2009, 328:119-126.

28. Fassett JT, Hu X, Xu X, Lu Z, Zhang P, Chen Y, Bache RJ: Adenosine kinase regulation of cardiomyocyte hypertrophy. Am J Physiol Heart Circ Physiol 2011, 300:H1722-H1732.

29. Ali SM, Brown EJ Jr, Nallapati SR, Alhaddad IA: Early angiotensin converting enzyme inhibitor therapy after experimental myocardial infarction prevents left ventricular dilation by reducing infarct expansion: a possible mechanism of clinical benefits. Coron Artery Dis 1998, 9:815-821.

30. Steinberg SF, Zhang H, Pak E, Pagnotta G, Boyden PA: Characteristics of the beta-adrenergic receptor complex in the epicardial border zone of the 5-day infarcted canine heart. Circulation 1995, 91:2824-2833.

31. Ryzhov S, Zhang Q, Biaggioni I, Feoktistov I: Adenosine A2B receptors on cardiac stem cell antigen ( $\mathrm{Sca}$ )-1-positive stromal cells play a protective role in myocardial infarction. Am J Pathol 2013, 183:665-672.

32. Toldo S, Zhong H, Mezzaroma E, Van Tassell B, Kannan H, Zeng D, Belardinelli L, Voelkel N, Abbate A: GS-6201, a selective blocker of the A2B adenosine receptor, attenuates cardiac remodeling following acute myocardial infarction in the mouse. J Pharmacol Exp Ther 2012 . 343:587-595.

33. Eltzschig HK, Bonney SK, Eckle T: Attenuating myocardial ischemia by targeting A2B adenosine receptors. Trends Mol Med 2013, 19:345-354.

34. Matherne GP, Linden J, Byford AM, Gauthier NS, Headrick JP: Transgenic A1 adenosine receptor overexpression increases myocardial resistance to ischemia. Proc Natl Acad Sci U S A 1997, 94:6541-6546.

35. Albrecht-Kupper BE, Leineweber K, Nell PG: Partial adenosine A1 receptor agonists for cardiovascular therapies. Purinergic Signal 2012, 8:91-99.

36. Lu Z, Fassett J, Xu X, Hu X, Zhu G, French J, Zhang P, Schnermann J, Bache RJ, Chen $Y$ : Adenosine $A 3$ receptor deficiency exerts unanticipated protective effects on the pressure-overloaded left ventricle. Circulation 2008, 118:1713-1721.

37. Du L, Gao ZG, Nithipatikom K, ljzerman AP, Veldhoven JP, Jacobson KA, Gross GJ, Auchampach JA: Protection from myocardial ischemia/ reperfusion injury by a positive allosteric modulator of the $A(3)$ adenosine receptor. J Pharmacol Exp Ther 2012, 340:210-217.

doi:10.1186/2191-219X-3-65

Cite this article as: Bousquenaud et al: Cardioprotective effects of adenosine within the border and remote areas of myocardial infarction. EJNMMI Research 2013 3:65

\section{Submit your manuscript to a SpringerOpen ${ }^{\odot}$ journal and benefit from:}

- Convenient online submission

- Rigorous peer review

- Immediate publication on acceptance

- Open access: articles freely available online

- High visibility within the field

- Retaining the copyright to your article

Submit your next manuscript at $>$ springeropen.com 